\title{
FORMAS DE VIOLENCIA EN LAS RELACIONES ENTRE LA CORONA DE ARAGÓN Y EL SULTANATO MAMELUCO (MEDIADOS DEL SIGLO XIII-MEDIADOS DEL SIGLO XV)
}

Damien Coulon

Université du Strasbourg

\section{RESUMEN}

Este artículo analiza las formas de violencia que se desarrollaron en las relaciones entre la Corona de Aragón y el sultanato mameluco de Egipto y Siria en la baja Edad Media. A pesar de entablar bastante buenas relaciones para proteger el gran comercio de especias, se pueden observar expediciones de piratería. Pero esta forma de violencia privada nunca amenazó realmente dichas actividades de negocio. Sin embargo, a partir del reinado de Alfonso el Magnanimo, empezó una nueva fase de relaciones, donde la violencia de estado, gracias al corso sobre todo, fue desarrollada como instrumento de presión. Aquel fenomeno era finalemente representativo de la creciente afirmación del estado en la baja Edad Media.

Palabras clave: corso, piratería, cruzada, seguros, sultanato mameluco.

\section{RÉSUMÉ}

Cet article analyse les formes de violence qui se développèrent dans les relations entre la couronne d'Aragon et le sultanat mamelouk d'Egypte et de Syrie à la fin du Moyen Âge. En dépit d'assez bonnes relations entretenues surtout pour ménager le grand commerce des épices, des expéditions de piraterie peuvent tout de même être relevées. Mais cette forme de violence privée ne menaça jamais vraiment ce négoce au long cours. Toutefois, à partir du règne d'Alphonse le Magnanime, commença une nouvelle phase de 
relations dans laquelle la violence d'Etat fut utilisée comme instrument de pression, principalement grâce aux activités de course. Ce phénomène était en fait représentatif de l'affirmation croissante de l'Etat à la fin du Moyen Âge.

Mots-clés: course, piraterie, croisade, assurances, sultanat mamelouk.

Reflexionar sobre el tema de la violencia a partir de investigaciones sobre las relaciones comerciales entre la Corona de Aragón y el sultanato mameluco de Egipto y Siria puede parecer paradójico porque se trata de uno de los escasos temas de relaciones pacíficas duraderas entre dos estados en la Edad Media. Es importante subrayar en primer lugar esta situación original en las relaciones entre cristianos y musulmanes en la Edad Media.

Aquellos contactos básicamente pacíficos se explican por los rasgos generales que caracterizan este potente estado musulmán. El sultanato mameluco sucedió al de los Ayyubides - los descendientes de Saladino - en 1250. Los mamelucos eran una clase de soldados esclavos que venían en realidad en su gran mayoría de las orillas del mar Negro, pero tomaron el poder en el contexto de la séptima cruzada y reinaron sobre Egipto y Siria hasta 1517. Hay que destacar también que aquel Estado ocupaba un lugar estratégico sobre la ruta de las especias, entre India y Europa, en la zona donde las especias tenían que pasar por caravanas del mar Rojo al Mediterraneo. Los monarcas catalano-aragoneses intentaron pues desarrollar buenas relaciones con los sultanes mamelucos para proteger el rico comercio que sus súbditos querían mantener con Egipto y Siria. Hay que añadir por fin que este objetivo de defensa de los intereses comerciales no se enfrentaba con otros de naturaleza más geopolítica y estratégica, ya que los dos estados se hallaban bastante alejados en orillas opuestas del Mediterraneo; pues ningún amenazaba directamente el otro o entraba en conflicto para el control de una zona maritima común, como lo podemos observar frecuentemente en las relaciones entre la Corona de Aragón y el Magreb, por ejemplo.

Pero, claro, si analizamos en detalle estas relaciones, notamos que de hecho, claras formas de violencia podían desarrollarse. Estas formas parecen por una parte muy lógicas en el contexto de relaciones lejanas con el Levante - caracterizado por proyectos de cruzadas y problemas de piratería -, pero por otra parte muy distintas según las épocas y los protagonistas. Total que es necesario examinar y situar, cada una en su contexto particular, lo que nos permitira entender mejor fenómenos básicos para las relaciones marítimas mediterráneas en la baja Edad Media. 


\section{I. ${ }^{\circ}$ CRUZADA DE JAIME I Y GUERRA DEL VESPRO (VISPERAS SICILIANAS): ¿UNA VIOLENCIA IMPOSIBLE?}

La primera forma de violencia que podemos notar en estas relaciones entre la Corona de Aragón y el sultanat mameluco es la cruzada que llevo, o mejor dicho que quiso llevar, el rey Jaime I al final de su reinado, en septiembre de 1269. Este nuevo proyecto de cruzada - la octava - estaba vinculado con el del rey de Francia, San Luís, que finalmente tuvo lugar al año siguiente. El rey catalanoAragónés estuvo acompañado por una potente flota de una treintena de navíos, lo que parece demostrar que queria luchar de manera decisiva contra los Mamelucos que asediaban los últimos puertos cristianos de Tierra Santa y de Siria.

Pero despues de zarpar, la flota encontró una tempestad que destruyó unos buques y Jaime I, enfermo, desembarcó en Aigües Mortes; y de ahí, volvió a su reino acompañado por la mitad de su ejército. La otra mitad - es decir 18 naves y 442 caballeros -, con dos infantes llegó a San Juan de Acre en Tierra santa. Pero la mayor parte de estas tropas tuvieron que regresar después de un mes, cuando se enteraron de que el monarca no llegaría. Finalmente quedaron menos de 200 caballeros con los dos infantes participando en la defensa de San Juan de Acre. Sin embargo, éstos también volvieron sin esperar a los cruzados franceses que, de todas formas, no habían alcanzado más lejos que las costas de Ifriqiya (Túnez)․․ Pues claro está, no es precisamente éste el episodio más violento de las cruzadas. Y parece bastante sintomático de estas buenas relaciones presentadas poco antes.

Esta expedición fracasada muestra perfectamente las dos razones que justifican parcialmente el carácter pacífico de aquellas relaciones entre la Corona de Aragón y el Sultanato Mameluco:

- La distancia entre los dos estados, en uno y otro lado de las cuencas mediterráneas, dificultaba organizar una verdadera guerra tan lejos de las bases de salida de las tropas.

- Además, el joven estado mameluco se asentaba con bases muy consolidadas; el más potente de los estados musulmanes del Mediterráneo de la baja Edad Media, lo que explica también su larga permanencia

Aquellas dos razones explican bastante bien, no solamente en el caso de la Corona de Aragón, las causas del fracaso de las Cruzadas a partir del final del s. XIII - hay que recordar que la octava fue la última - a pesar de proyectos de grandes alianzas con el imperio de los mongoles para dejar en medio a los mamelucos - precisamente, el rey Jaime I había enviado un embajador, el perpiñanés Jaume Alarich, a la corte del gran khan de los Mongoles².

1 Jean Richard, Histoire des croisades, Paris, Fayard, 1996, pp. 438-439.

2 Ibid. p. 438. 
Algunos años mas tarde, el episodio de la guerra del Vespro (1282) (o Vísperas Sicilianas) enfrentó esta vez el poder del Papado con la Corona de Aragón. El rey Pedro el Grande se encontró de esta forma muy aislado en el marco del mundo cristiano. Lógicamente, buscó la alianza de los musulmanes, en particular el Estado más sobresaliente, los Mamelucos.

Así fue firmado en abril de 1290 un primer tratado oficial entre Alfonso III - sucesor de Pedro el Grande - y el sultán al-Mansûr Qalawûn. Preveía una verdadera colaboración militar entre los dos estados: el rey tenía que socorrer al sultán en caso de agresión cristiana y en particular de una nueva cruzada; en cambio, el acceso de los puertos de Egipto y de Siria era facilitado a los súbditos del rey y también el de Jerusalen a los peregrinos cristianos. Además es posible que hubiera una cláusula secreta de ayuda pecuniaria del sultán en favor del rey, para sufragar los gastos de la lucha contra sus enemigos cristianos - el Papa y los reyes de Francia y de Nápoles.

Esta estrategia puede parecer muy atrevida y original. Pero en realidad no era desconocida: el emperador Federico II de Hohenstaufen ya habia negociado con el sultán ayyubide al-Kamîl en 1229 el famoso tratado de Jaffa, para lograr el dominio de la ciudad de Jerusalen a pesar de ser excomulgado por el Papa. Y ya se sabe bien que durante las Vísperas Sicilianas, los reyes de Aragón pretendían defender la herencia de los Staufen contra los Angevinos, que defendían la estrategia del Pontificado. Este nuevo contexto explica pues las buenas relaciones entre los dos estados que tenían que mantenerse también después de la muerte de los dos monarcas. Asi se comprende que los respectivos sucesores de Alfonso III y de al-Mansûr Qalawûn, Jaime II y al-Ashraf Khalîl confirmaron el mismo tratado en enero de 1293 que se mantuvo finalmente hasta el siglo XV³. Estos acuerdos de alto nivel demuestran porque luego los monarcas catalano-aragoneses nunca vendieron licencias de corso contra Egipto y Siria y porque eximían a estos dos países de las licencias otorgadas contra los estados musulmanes del Maghreb ${ }^{4}$.

\section{II. $^{\circ}$ FORMAS DE VIOLENCIA EN LAS RELACIONES COMERCIALES (SIGLO XIV)}

A pesar de este excelente ambiente diplomático, podemos encontrar claras formas de violencia en el marco del gran comercio que se desplego entre la Corona de Aragón, especialmente su puerto de Barcelona, y el Sultanato Mameluco.

3 Damien Coulon, Barcelone et le grand commerce d'Orient. Un siècle de relations avec l'Egypte et la Syrie-Palestine, Barcelona, Madrid, Institut Europeu de la Mediterrània, Casa de Velazquez, 2004, pp. 44-45.

4 Ibid., p. 204. 
De hecho, se desarrolló un tipo de violencia privada que suscitaban la riqueza y la cantidad de mercancías intercambiadas entre las dos orillas del Mediterráneo. Quiero hablar, claro, de la piratería y del corso que practicaron varios estados rivales de la Corona de Aragón y también los súbditos de dicho Estado.

Varios trabajos ya han tratado de este tema ${ }^{5}$, atractivo, pero dificil porque los piratas dejan pocas huellas escritas de sus acciones. Pero a veces tenemos quejas dirigidas a las autoridades de los piratas, cuando eran identificados, o de los corsarios cuando sus robos no eran justificados por una situacion oficialmente conflictiva $^{6}$. Sabemos por ejemplo que el genovés Pietro Re, que según fuentes genovesas es presentado como cónsul de los catalanes en Chipre - una situación que de vez en cuando podía ocurrir - aprovechó su cargo para robar en febrero de 1416 todo el contenido de una nave barcelonesa (la de Bartomeu Amar) que se dirigía hacia Beirut, en el pricipal puerto de la isla, Famagusta. Ya que la Corona de Aragón estaba en paz con la republica de Génova, el patrón de la nave y los mercaderes se quejaron oficialmente y excepcionalmente, las autoridades genovesas aceptaron pagarles las indemnizaciones ${ }^{7}$.

Un segundo caso anterior es también muy interesante, ya que el pirata era esta vez un súbdito de la Corona, y que intentó jugar con la ambigüedad entre corso y pirateria. Se trata de Guillem Ramon de Montcada que desde la isla de Cerdeña atacó primero a varias naves hafsíes (tunecinas) poco antes de 1386. Conocemos estos acontecimientos gracias a quejas del sultán mameluco y a las respuestas enviadas por el rey Pedro el Ceremonioso que justificó aquellos expolios por la guerra entre la Corona de Aragón y el emirato hafsí de Túnez en este período. Ramon de Montcada actuaba pues como corsario en el marco de un conflicto bélico y se trataba pues de una forma legal de violencia. Pero unos meses más tarde, los registros de la cancilleria real revelan que el «corsario» habia atacado también a naves catalanes - la del barcelones Francesc Saclosa, seguramente en 1386 - y que finalmente se manifestaba como un pirata incontrolable que el rey tuvo que condenar y castigar ${ }^{8}$.

5 Entre las numerosas obras dedicadas a este tema, ver por ejemplo, Pinuccia F. Simbula, Corsari e pirati nei mari di Sardegna, Cagliari, 1993; Maria Teresa FerRer i Mallol, Corsarios castellanos y vascos en el Mediterraneo medieval, Barcelona, CSIC, 2000.

6 Asi se caracteriza la diferencia básica entre pirateria y corso: mientras que un pirata actua para si mismo, un corsario actua bajo una autoridad que justifica sus robos por situaciones de guerra o de represalias contra enemigos precisos; estos robos son entonces compartidos con aquella autoridad. Pero a menudo esta diferencia puede desaparecer fácilmente, ya que numerosos corsarios practicaban también la pirateria; ver a continuación el caso de Guillem Ramon de Montcada.

7 Cf. Laura Balletto, «Fra Genovesi e Catalani nel Vicino Oriente nel secolo XV», in Maria Teresa Ferrer i Mallol ed., Els catalans a la Mediterrània oriental a l'Edat Mitjana, Barcelona, Institut d'Estudis Catalans, 2003, p. 172 y D. Coulon, Barcelone et le grand commerce d'Orient, op. cit., p. 212.

8 D. Coulon, Barcelone et le grand commerce d'Orient, op. cit., pp. 203-204. 
No tenemos a menudo tantos detalles y además no sirve mucho multiplicar los ejemplos aislados. Es seguramente más útil hacer observaciones generales, a pesar de aquel limite documental claro:

1. Una cartografía de las zonas más peligrosas, donde las agresiones piráticas o de corso podían ocurrir de forma frecuente, puede ser esbozada. Por ejemplo en los alrededores de Cerdeña, una isla en realidad mal controlada por la Corona de Aragón y disputada entre esta misma y la república de Génova durante casi todo el siglo XIV. Aquel contexto de desorden favorecia la instalación de bases de piratas que podian gozar así de un cierto poder y actuar sin apenas ser vigilados. Después de la pacificacion de Cerdeña al principio del siglo XV, el centro de gravedad pirático se desplazó hacia otra isla del Mediterráneo Oriental: Rodas. A pesar de ser bien controlada por los caballeros de San Juan de Jerusalén, este enclave parecía también una cabeza de puente cristiana en un Mediterráneo Oriental cada vez más dominado por los musulmanes y quizás por aquella razon los caballeros de San Juan toleraban la presencia y las actividades de numerosos piratas cristianos. Pero esta situación provocó las numerosas quejas y hasta las persecuciones de otras autoridades a menudo cristianas, por ejemplo las de Venecia, contra ciertos piratas - y entre ellos el temible catalán Nicolau Sant Pere que actuó sobre todo entre 1416 y 1420 .

2. ${ }^{\circ}$ A menudo, los piratas son en realidad patrones de naves ordinarios que aprovechan ocasiones para atacar otro buque aislado o poco defendido. Y estas ocasiones ocurren fácilmente en medio del mar donde no hay testigos, ni sobre todo representantes armados de un poder público. Lo sabemos gracias a la confrontación entre fuentes de diferentes origenes. Por ejemplo, en contratos notariales catalanes observamos patrones de naves y mercaderes que preparan su viaje comercial, muy honradamente, cargando las mercancías a bordo; pero en documentos de otro origen -italianos o arabes por ejemplo-, estos patrones de naves son denunciados como piratas que han abatido buques extranjeros durante su viaje. Es lo que podemos notar en el caso de los patrones Marti Vicens y Nicolau Pujada que zarpan, cada uno con su nave, para un viaje comercial hacia el Levante en mayo de 1394, y que son llamados piratas en el relato de peregrinación del notario de Campania Niccolo Martoni, cuando los encuentra en Rodas ${ }^{9}$. Podemos enterarnos también de aquel doble papel de patrón de nave y de pirata, cuando uno de ellos aparece

9 Ibid., p. 207. 
en los contratos notariales a la vuelta de su viaje, compartiendo escrupulosamente el botín realizado con sus marineros. Estos casos de piratas ocasionales no son aislados y tal vez los agresores podían convertirse tambien en víctimas, unos documentos lo evidencian.

3. ${ }^{\circ}$ Esta segunda precisión nos permite entender mejor porque el ritmo de estas agresiones piráticas iba creciendo con el tiempo. De hecho, los testimonios de ataques son sustancialmente más numerosos con el paso del tiempo en las fuentes, sobre todo los testimonios extranjeros que denuncian agresiones de piratas catalanes. Claro, se puede preguntar si aquellas fuentes no son un espejo que deforma la realidad, exagerando el papel negativo de los extranjeros, y si en realidad la piratería no aumentase de manera general. Pero pienso que aquellas fuentes extranjeras reflejan bien otra certeza: el crecimiento de las actividades comerciales catalanes en el Mediterráneo durante la segunda mitad del siglo XIV, que podemos contemplar también gracias a otras comprobaciones, como el número creciente de las naves que zarpan de Barcelona y de las inversiones en el comercio ${ }^{10}$.

4. ${ }^{\circ}$ La ultima observación sobre la piratería confirma esta clara impresión de aumento del volumen mercantil: distinguimos también en el mismo periodo - segunda mitad del siglo XIV - un crecimiento de los esfuerzos para protegerse contra las agresiones en el mar. Lo constatamos primero con la tentativa de utilizar galeras, es decir buques de combate, cuyos remeros podían convertirse en defensores de las mercancías cargadas, sobre todo cuando se trataba de mercancías caras transportadas durante largos viajes, como las especias traídas del Levante. Pero en realidad, a pesar de tentativas repetidas al final del siglo XIV y en los años 1430 en los viajes comerciales entre Barcelona y el Oriente mediterráneo, esta experiencia fue abandonada seguramente a causa de su importante costo; porque había que pagar los remeros, mientras que en otros tipos de navíos, la mano de obra no resultaba tan numerosa ${ }^{11}$.

Pero había otra medida mucho más económica: la utilización de contratos de seguros a prima, que de hecho van desarrollándose y aumentando a partir del siglo XV - después de otro tipo de contrato más antiguo: los seguros marítimos. Según la fórmula jurídica habitual, estos acuerdos ofrecían garantías contra los riesgos de mar y de la gente (ad risicum maris et gentium), es decir contra los riesgos de pérdida de las mercancías a causa de tempestades o de ataques de piratas

${ }^{10}$ Ibid., pp. 168-176, 296-302.

${ }^{11}$ Ibid., pp. 152-157. 
por ejemplo. La multiplicación de aquellos contratos y la especialización de algunos mercaderes en la actividad de seguro en el siglo XV demuestran claramente que la inseguridad era un problema permanente en los viajes comerciales ${ }^{12}$. Además, muestran también, por su permanencia, que constituían una solución contra problemas de violencia que podemos calificar de cotidiana y ordinaria ${ }^{13}$.

Para acabar con aquel tema de la violencia en las actividades comerciales, hay que analizar también rápidamente la actitud de los árabes de Egipto y de Siria. Es interesante apuntar que es muy difícil encontrar testimonios de actividades piráticas por su parte al final de la Edad Media ${ }^{14}$. Esto se explica en realidad por su progresiva renuncia a participar al gran comercio en el Mediterráneo: ya no navegaban hacia los puertos occidentales en los siglos XIV y XV; se limitaban a vender las especias a los cristianos en los mercados de Siria y Egipto.

Sin embargo si existen quejas contra su actitud en las fuentes occidentales. De hecho, los Mamelucos percibían muchas tasas sobre la venta de las especias, ya que sabían que los mercaderes occidentales tenían que venir a sus países para comprarlas. Algunos agentes de la aduana - al-diwân - tenían pues a menudo la tentación de abusar de esta situación para exigir algo más que los impuestos legales. Conocemos por ejemplo que los patrones de buques cristianos tenian que entregar sus velas cuando entraban en los puertos de Siria y de Egipto y que sólo podían recuperarlas cuando habian pagado todos los impuestos; entonces algunos responsables de la aduana aprovechaban esta situación para solicitar más cantidades de las que acostumbraban. También podríamos sospechar en estas quejas exageraciones en contra de los musulmanes por parte de los cristianos; pero el viajero musulman Ibn Yubayr confirma en el relato de su peregrinacion - su rihla - del final del siglo XII, que los viajeros musulmanes también habían perdido muchas de sus cosas en la aduana de Alejandría, por culpa de los agentes y de la muchedumbre que se hallaba allí.

Por cierto, no se trata de violencia fisica, al contrario de la piratería. Pero aquellos abusos representaban coacciones brutales e ilegales. Constituían pues otras formas de violencia cotidiana y ordinaria por su carácter repetido.

${ }^{12}$ Ibid., pp. 261-265.

${ }^{13}$ A propósito de la violencia cotidiana en la sociedad medieval, cf. David Nirenberg, Communities of Violence, Princeton, Princeton University Press, 1996.

${ }^{14}$ Una comprobación que contrasta con las actividades piráticas magrebíes en el mismo periodo; cf. María Dolores Lopez Pérez, La Corona de Aragón y el Magreb en el siglo XIV : 13311410, Barcelona, CSIC, 1995, pp. 686-729 y Dominique VALÉRIAN, Bougie port maghrébin 1067-1510, Roma, Ecole Française de Rome, 2006, pp. 421-501. 


\section{III. $^{\circ}$ NUEVAS FORMAS DE VIOLENCIA: VIOLENCIA DE ESTADO EN EL SIGLO XV}

A partir del reinado de Alfonso el Magnánimo acaban las relaciones diplomáticas pacíficas entre ambos estados en parte a causa de una crisis cuyas raíces remontaban a algunos años antes de su llegada al trono en abril de 1416. Todo empezó con una acción pirática que tuvo lugar en septiembre de 1412: un patrón de buque valenciano que tenía que traer mercaderes magrebíes de Alejandría a Túnez los desembarcó finalmente en Valencia, contra su voluntad, vendiendo sus mercancías iy los mercaderes tambien como esclavos! (En otra versión se dice que un embajador del sultán se encontraba también entre los pasajeros musulmanes). Claro, aquel robo ocasionó represalias por parte del sultán al-Mu'ayyad Shaykh que infligió primero una multa colectiva a los mercaderes catalanes presentes en Egipto y que convocó luego a su cónsul - que representaba todos los subditos de la Corona -, Francesc Satria, en El Cairo donde fue físicamente castigado. Recibió una paliza tan fuerte que tuvo que ser curado durante seis meses según nos aclara el testimonio del hombre de negocios de origen veneciano Emmanuele Piloti ${ }^{15}$. También le era prohibido salir de Alejandría, ya que había aconsejado a los mercaderes de la Corona huir para evitar represalias.

Así pues, algunos meses antes de llegar al trono, el infante Alfonso preparó minuciosamente una verdadera expedición de corso que aparece como una venganza contra estas medidas humillantes: envió dos o tres navíos de comercio - las fuentes divergen - a Alejandría donde llegaron en agosto de 1416; ahí los súbditos de la Corona desarrollaron operaciones comerciales durante dos semanas para dar la impresión que eran realmente mercaderes que querían reestablecer de nuevo los contactos. Pero de forma premeditada para ellos e in extremis para los musulmanes, una mañana atacaron la aduana matando y heriendo a numerosos egipcios y raptando a los más jóvenes, que eran unos 80, mientras que el cónsul había podido refugiarse en uno de los barcos. A la vuelta en Barcelona, estos jóvenes fueron vendidos como esclavos y Alfonso, ahora rey, percibió una quinta parte del botín como de costumbre en las operaciones de corso. El sultán no pudo tomar nuevas medidas de castigo contra los mercaderes de la Corona, ya que Alfonso había ordenado algunos meses antes de esta expedición a los pocos que se habían quedado, salir del sultanato. Hubo entonces una ruptura duradera de las relaciones entre los dos estados, y durante trece años - entre 1416 y 1429 - no hubo cónsul de los súbditos de la Corona de Aragón en el sultanato ${ }^{16}$.

${ }^{15}$ Emmanuel Piloti, Traité sur le passage en Terre Sainte (1420), ed. Pierre H. Dopp, Louvain, Paris, Publications de l'Université Lovanium de Léopoldville, 1958, p. 232-233.

${ }^{16} \mathrm{D}$. Coulon, «Un tournant dans les relations catalano-Aragonaises avec la Méditerranée orientale: la nouvelle politique d'Alphonse le Magnanime (1416-1442 environ)», in Guido 
Detrás de aquellos acontecimientos lo que me parece relevante subrayar, es que primero el nuevo rey cambia completamente de política con respecto al sultanato mameluco; y sobre todo que adopta como nueva politica «diplomática» métodos violentos que, como hemos descrito más arriba, corresponden a objetivos privados, de individuos que actuan para su propio interés. De hecho, aquella expedición de corso contra los súbditos del sultán mameluco no fue aislada durante el reinado de Alfonso el Magnánimo, como veremos posteriormente. Con el, el corso se convierte en instrumento político-militar de estado.

Y es interesante incidir en que la linea política de los sultanes mamelucos también se modificó, un poco más tarde, sobre todo con la llegada al poder de Barsbay en 1422. Como había comprendido que la llegada de las especias en Egipto y Siria era una fuente inagotable de ingresos gracias a las tasas sobre el comercio para su hacienda, impuso nuevas medidas que tenían que enriquecer aún más su tesoro: estableció un monopolio sobre la venta de las principales especias, es decir que tenían que ser vendidas por agentes del sultán y no libremente por mercaderes, lo que corresponde al principio del matyar ${ }^{17}$; y claro los beneficios iban directamente a sus arcas, pero para aumentar aun más sus ingresos, habia impuesto precios más altos que los del mercado. Habíamos destacado para el siglo XIV una tendencia a los abusos sobre los impuestos por parte de los agentes de la aduana, pues podríamos decir que el nuevo sultán Barsbay aplica al nivel más alto el mismo tipo de actitud para enriquecerse.

Obviamente, hubo muchas quejas y tentativas de boicotear el sultanato por parte de los mercaderes venecianos por ejemplo, pero no cambiaron las decisiones de Barsbay. De manera inesperada, fue en este contexto defavorable que Alfonso el Magnánimo intentó una nueva política de reconciliación con Barsbay, seguramente bajo la presión de los mercaderes catalanes privados de una importante fuente de ingresos. Los dos monarcas negociaron a través de sus embajadores enviados en Rodas en 1429 y 1430 un importante tratado de paz y amistad. Entre sus principales decisiones, se prohibía la política de los monopolios para el sultán y se preveía severas medidas de represalias contra expediciones piráticas por parte de los subditos del rey; asimismo una gran parte de los acuerdos negociados en los tratados de 1290 y 1293 fueron confirmados.

Pero este tratado no fue aplicado durante mucho tiempo: ya en 1432 el sultán Barsbay imponía de nuevo su lucrativa política de monopolios, a la cual el

D’Agostino y Giulia Buffardi ed., La Corona d'Aragona ai tempi di Alfonso il Magnanimo. XVI Congresso d'Historia della Corona d'Aragona, Napoles, 2000, t. II, pp. 1055-1079 e Idem, Barcelone et le grand commerce d'Orient, op. cit., pp. 204-205 y 211-212.

${ }^{17}$ Cf. Claude Cahen, Orient et Occident au temps des croisades, Paris, Aubier Montaigne, 1983, pp. 136-137. 
Magnánimo contestó con una nueva expedición de corso llevada por el principe de Taranto en las aguas de Siria. Cada monarca enseñaba así que no actuaba solamente dentro de un marco contextual preciso, sino que se seguía una nueva linea político-diplomática más dura, mas violenta, ya definida pocos años antes. Es también sintomático señalar que Alfonso el Magnánimo utilizó de nuevo el tema de la cruzada para justificar su acción armada contra el sultán Barsbay; pero, claro, al fin y al cabo no fue nada más que retórica.

Así podemos entender que esta nueva política más férrea del siglo XV no era nada más que una aplicación más taxativa o rigurosa del Estado o mejor dicho de una instrumentalización de las violencias ordinarias y de tipo privado de la época anterior. La simetría de esta evolución en cada uno de estos dos estados, tan lejos y tan diferentes culturalmente, puede sorprender a primera vista; pero en realidad se explica bien por el desarrollo más general hacia una afirmación del Estado, en el Proximo Oriente como en Occidente, al final de la Edad Media. Y claro, la violencia constituía uno de los medios para alcanzar aquella afirmación y constitución del Estado; pero en manos del monarca, se trataba de otro tipo, otra escala de violencia - como lo observamos por ejemplo en el desarrollo de la guerra de 100 años entre Francia e Inglaterra en la misma época- .

Como conclusión general, podemos realizar tres observaciones básicas:

1. A pesar de prestar atención al principio sobre las relaciones comerciales entre Cataluña y Egipto y Siria, comprobamos que esta actividad permite sin embargo estudiar diferentes manifestaciones de violencia. Esta observación se explica porque el comercio necesita paz y tranquilidad, que en cierto modo es un poco el contrario de la violencia: distinguimos de manera muy sintomática que la actividad comercial se interrumpe precisamente cuando ocurren acontecimientos violentos como guerras, expediciones piraticas o de corso. Pues, el comercio revela «en negativo» los acontecimientos violentos.

2. Así hemos podido identificar tres tipos bastante diferentes de violencias en estas relaciones, que corresponden a diferentes épocas y protagonistas:

- violencia cruzada que no podemos aplicar a las relaciones entre la Corona de Aragón y el sultanato mameluco, pero que es representativa de los siglos XII y XIII;

- violencia de estado representativa del fenómeno de consolidación del estado en el siglo XV;

- violencia pirática privada y endémica durante todos estos siglos y aún largo tiempo después.

3. En este contexto de buenas relaciones donde la violencia se expresa difícilmente entre los dos estados principalmente estudiados, constatamos 
que finalmente se cristaliza, sin embargo entre otros estados, segun una lógica de sistema de alianzas: por un lado, entre la Corona de Aragón y su gran rival económico y marítimo: la república de Genova; por otro lado, entre el sultanato mameluco y el reino cristiano de Chipre. Aquellas relaciones conflictivas, se desencadenaban fácilmente con violencia en episodios que he preferido dejar de lado y que necesitarian casi otra comunicación - como el saqueo de Alejandría en 1365 por el rey de Chipre Pedro I en el cual participaron catalanes, genovesos y venecianos y luego la expedición del sultán Barsbay en Chipre, cuando captura su rey Janús en 1426; o la batalla naval en la que se oponen navíos catalanes y genovesos en el mismo puerto de Alejandría en 1411, sin hablar de las numerosas operaciones bélicas entre los mismos enemigos en la guerra del principio de los años 1350, a la cual participaron también los venecianos ${ }^{18}$.

${ }^{18}$ Sobre estos acontecimientos, ver por ejemplo, George Hill, A History of Cyprus, 3 vol., Cambridge, 1940-1948, reed. Londres, 1972, especialmente el t. II; Laura BALLETTO, «Chio dei Genovesi tra rivolta maonese, corsari catalani ed attachi veneziani», Anuario de Estudios Medievales, 24, 1994, pp. 481-486; M.T. FerRer i MAllol, «Una flotta catalana contro i corsari nel Levante (1406-1409)», in Laura Balletto ed., Oriente e Occidente tra Medioevo e Età Moderna, Studi in onore di Geo Pistarino, Genova, Glauco Brigati, 1997, pp. 352-355; Eadem, «Incidència del cors en les relacions catalanes amb l'Orient (segles XIII-XV)», in M.T. Ferrer i Mallol ed., Els catalans a la Mediterrània oriental, op. cit., pp. 272-273; L. BAlletto, «Fra Genovesi e catalani», op. cit., pp. 167-190 y D. Coulon, Barcelone et le grand commerce d'Orient, op. cit., pp. 48-50 y 57. 